\title{
REVIEW
}

\section{Hydrogels for cardiac tissue engineering}

\author{
Gulden Camci-Unal ${ }^{1,2}$, Nasim Annabi ${ }^{1,2,3}$, Mehmet R Dokmeci ${ }^{1,2,3}$, Ronglih Liao ${ }^{4}$ and \\ Ali Khademhosseini ${ }^{1,2,3,5}$
}

\begin{abstract}
Cardiac failure is a critical condition that results in life-threatening consequences. Due to a limited number of organ donors, tissue engineering has emerged to generate functional tissue constructs and provide an alternative mean to repair and regenerate damaged heart tissues. In this paper, we review the emerging directions associated with cardiac tissue engineering approaches. In particular, we discuss the use of hydrogels in repair and regeneration of damaged hearts. Because of their tissue-like biological, chemical and mechanical properties, hydrogels represent a potentially powerful material for directing cells into functional cardiac tissues. Herein, we will summarize both traditional and next-generation hydrogels with conductive, elastomeric and oxygen-releasing capabilities that can promote vascularization and stem cell differentiation to form properly functioning cardiac tissues.
\end{abstract}

NPG Asia Materials (2014) 6, e99; doi:10.1038/am.2014.19; published online 16 May 2014

Keywords: biomaterials; cardiac tissue engineering; hydrogels; regenerative medicine; stem cells

\section{INTRODUCTION}

According to the American Heart Association, cardiovascular diseases are the number one cause of death globally. ${ }^{1}$ In particular, myocardial infarction (MI), which is widely known as heart attack, is one of the major causes of death associated with cardiovascular disease. MI evokes obstruction of blood flow to the heart, leading to oxygen deficiency in the heart muscles and ultimately cell death. ${ }^{2}$ As a result, the remaining muscle tissue undergoes structural and functional remodeling indicated by ventricular wall thinning and chamber dilatation. ${ }^{3}$ The limited regeneration capability of the adult cardiomyocytes in the heart prevents the tissue to regenerate fully on its own. ${ }^{3,4}$ Thus there is a tremendous need for new treatment strategies to remedy dysfunctional hearts.

Synthetic implants to replace heart function, such as left ventricular assist devices, have been shown to be a useful therapeutic method for many years; however, they have a number shortcomings, such as limited lifespan and potential issues associated with infection and thrombosis. ${ }^{5}$ Therefore cardiac transplantation remains a viable option to treat end-stage heart failure patients. ${ }^{2}$ However, due to the limited number of organ donors and potential rejection problems, innovative alternative approaches are needed. ${ }^{6,7}$

Direct injection of cells into the cardiac muscle has been used as a method of delivering cells into the infarcted tissue. ${ }^{4,5,8,9}$ In vivo, this approach has been shown to achieve some success in regaining muscle function after MI. ${ }^{10,11}$ However, $\sim 90 \%$ of the injected cells die after implantation, demonstrating the importance of vasculature and appropriate tissue microarchitecture for cardiac tissue regeneration. ${ }^{2,8}$ In particular, environmental stress associated with the lack of a three dimensional (3D) flexible biomimetic microenvironment and direct exposure of single cells to oxygen tension, free radicals and inflammatory cytokines induce cell death. ${ }^{10}$ Therefore, there is a significant need for engineered biomaterials that can be used as 3D matrices to efficiently deliver cells to the damaged cardiac muscle and facilitate myocardial regeneration.

To this end, tissue engineering strategies have been developed to replace damaged or diseased cardiac tissues. ${ }^{2,4,9,12,13}$ Although tissue engineering platforms have been successfully used for engineering of avascular organs, generating artificial substitutes for highly vascularized cardiac tissues remains remarkably challenging. ${ }^{14}$ Because of their highly tunable features, engineered hydrogels have been used to address these limitations.

Hydrogels are composed of 3D hydrophilic polymer networks that can swell upon exposure to water. ${ }^{15}$ This property enables hydrogels to mimic specific aspects of the tissue microenvironments. ${ }^{16,17}$ Hydrogels are extensively used in cardiovascular tissue engineering owing to their ability to support cell adhesion and growth., ${ }^{2,18,19}$ Additionally, hydrogels can be patterned by using microfabrication techniques to induce vascularization of engineered cardiac constructs or to direct the alignment of cardiac cells and consequently improve their functions. ${ }^{14}$ Hydrogels provide mechanical support for cardiac

${ }^{1}$ Division of Biomedical Engineering, Department of Medicine, Brigham and Women's Hospital, Harvard Medical School, Cambridge, MA, USA; ${ }^{2}$ Harvard-MIT Division of Health Sciences and Technology, Massachusetts Institute of Technology, Cambridge, MA, USA; ${ }^{3}$ Wyss Institute for Biologically Inspired Engineering, Harvard University, Boston, MA, USA; ${ }^{4}$ Cardiac Muscle Research Laboratory, Cardiovascular Division, Department of Medicine, Brigham and Women's Hospital, Harvard Medical School, Boston, MA, USA and ${ }^{5}$ WPI-Advanced Institute for Materials Research, Tohoku University, Sendai, Japan

Correspondence: Professor A Khademhosseini, Department of Medicine, Brigham and Women's Hospital, Harvard Medical School, 65 Landsdowne Street PRB, Room 252, Cambridge, MA 02139, USA.

E-mail: alik@rics.bwh.harvard.edu

Received 14 October 2013; revised 8 January 2014; accepted 22 January 2014 
cells to deposit extracellular matrix (ECM) and form the newly synthesized tissue as they degrade. ${ }^{3,10}$ Furthermore, physical and chemical properties of hydrogels can be easily tuned to enhance cell viability and function. Therefore, hydrogels are attractive materials for regeneration of the damaged myocardium.

Hydrogels from both natural and synthetic sources have been used for cardiac tissue engineering. Some of the widely used hydrogels include collagen, ${ }^{2}$ gelatin, ${ }^{2}$ Matrigel, ${ }^{20}$ alginate, ${ }^{21}$ fibrin, ${ }^{2}$ poly(2-hydroxyethyl methacrylate) (PHEMA), ${ }^{22}$ poly(Nisopropylacrylamide) (PNIPAAM) ${ }^{23}$ and poly(ethylene glycol) (PEG). ${ }^{3}$ These materials can be utilized either by themselves or in combination with cells. ${ }^{24}$ In addition, growth factors can be embedded within these hydrogels to promote tissue formation. ${ }^{25}$

In this paper, we will discuss traditional and next-generation hydrogels with oxygen-releasing, elastomeric and conductive features for their use in cardiac tissue engineering. In addition, we will summarize hydrogel-based platforms which can be used to promote vascularization and stem cell differentiation, for engineering functional cardiac tissues. Furthermore, we will provide examples that utilize various hydrogels, cell sources and novel delivery strategies to repair or regenerate the broken heart.

\section{TRADITIONAL HYDROGELS FOR CARDIAC TISSUE ENGINEERING}

Hydrogels have been widely used in regenerative medicine owing to their highly tunable chemical, physical and mechanical properties. ${ }^{17,26-31}$ In particular, hydrogel-based materials have been successfully utilized in cardiac tissue engineering as structural/ mechanical supports to maintain cells in place, ${ }^{2}$ promote vascularization, ${ }^{32}$ deliver small molecules, ${ }^{33}$ transplant cells ${ }^{17}$ and fabricate cardiac patches. ${ }^{34}$ The ability to tune the physical properties of hydrogels provides unique opportunities to control various cellular behaviors, including migration, proliferation and differentiation, and has strong influence on tissue healing following transplantation.

Hydrogels can be delivered into the heart to enhance the function of cardiac tissue without the use of cells. For instance, PNIPAAM, a temperature-sensitive material, was used in combination with hydroxyethyl methacrylate-poly(trimethylene carbonate) and acrylic acid (AAc) for delivery into the MI area in a rat model (Figure 1). ${ }^{23}$ These hybrid hydrogels were shown to reduce the dilation of the left ventricle and improve cardiac function. In another study, it was shown that implanted plastic-reinforced PHEMA gels in a canine model had no significant inflammation after one year, demonstrating their potential as pericardial substitutes. ${ }^{22}$

In addition to its non-cellular applications, temperature-sensitive PNIPAAM has also been used in combination with cells. ${ }^{2}$ For example, a bilayered hydrogel from a temperature-responsive and non-responsive polymer was generated to investigate its potential use as an implantable cell-loaded delivery system. Neonatal rat cardiomyocytes were cultured on the hydrogels until they reached confluence. Subsequently, temperature was lowered, and the hydrogel sheets were curled/rolled into tubes owing to the difference in swelling properties of the bilayered polymers, resulting in the formation of cell-laden hydrogels for catheter-based delivery systems.

PEG hydrogels have been extensively used for engineering functional cardiac tissues. In one study, cardiomyocytes were encapsulated within Arginine-Glycine-Aspartic acid (RGD)-modified PEG hydrogels. ${ }^{35}$ It was found that RGD-conjugated PEG hydrogels afforded significantly higher cell viability compared with their non-modified counterparts. Similarly, PEG in combination with thiol-modified hyaluronic acid was used to generate hydrogels that increased their stiffness over time. ${ }^{36}$ The hybrid hydrogels were seeded with pre-cardiac cells from chicken embryo, and their cardiogenic differentiation was studied as a function of time. To closely mimic the conditions that occur during morphogenesis of the heart, the stiffening behavior of the hydrogel was tuned by varying the molecular weight of the crosslinker. The cells that were seeded on these hydrogels expressed significantly higher amount of cardiacspecific markers compared with the control gels with constant stiffness. In addition, muscle fibers were found to be more mature on the stiffer hydrogels.

Although hydrogels from synthetic materials (for example, PEG, PHEMA and PNIPAAM) demonstrated suitable mechanical properties, the use of native ECM molecules in their synthesis may lead to the formation of biomimetic constructs for cardiac regeneration. For example, Matrigel is a hydrogel that has been isolated from Engelbreth-Holm-Swarm tumors in mice. Previously, Matrigel has been used as a scaffold for delivery of human mesenchymal stromal cells into a mouse MI model, which was shown to improve cellular viability. ${ }^{37}$ In another report, neonatal cardiomyocytes were suspended in Matrigel and seeded within collagen foams. ${ }^{20}$ The in vitro constructs were demonstrated to become functional cardiac muscle tissues by utilizing pulsatile electrical stimulation. Similarly, Matrigel and collagen were mixed in a 1:1 ratio and used to encapsulate rat skeletal muscle cells and implanted in a rat $\mathrm{MI}$ model to improve cardiac function. ${ }^{38}$

Fibrin is another natural gel that has been broadly used for cardiac cell encapsulation. In one example, neonatal rat cardiomyocytes were encapsulated in fibrin hydrogels to study the influence of cellular alignment on the function of the biomimetic tissues. ${ }^{39}$ Gel contraction took place due to the presence of cells within the hydrogel constructs. Degradation of the fibrin gel enabled the encapsulated cardiomyocytes to deposit their own ECM, remodel and form aligned fibers. The results indicated that the alignment of cells augmented the twitch force upon electrical stimulation owing to the enhanced formation of gap junctions between cells. ${ }^{39}$ Similarly, aligned cardiomyocytes within 3D fibrin hydrogels were shown to maintain their synchronous beating behavior even after 2 months of in vitro culture. ${ }^{40}$ Collectively, these studies indicated that the alignment of cardiomyocytes has important implications for their function. In another study, primary cardiomyocytes that were transplanted into adult rats within fibrin gels were shown to provide a functional, vascularized and contractile tissue after 3 weeks. $^{32}$

Decellularized cardiac tissues have also attracted significant attention for cardiac regeneration. In one study, pig myocardial ECM was used to synthesize hydrogels. ${ }^{41}$ The ECM material was isolated by processing decellularized porcine heart muscle. After characterization of the structure and composition of the ECM hydrogels, their potential to promote vascularization was investigated using endothelial cells (ECs) and smooth muscle cells. In addition, the ECM hydrogels supported high cardiomyocyte viability. Decellularized ECM-based hydrogels have strong potential for in vivo studies, particularly for delivery of cell-laden gels into the myocardium via syringe or catheter-based approaches.

\section{EMERGING HYDROGELS FOR ENGINEERING CARDIAC TISSUES}

Traditional hydrogels have been commonly used for engineering cardiac tissues; however, due to the current challenges there is a tremendous demand for the synthesis of next-generation hydrogels. 
a

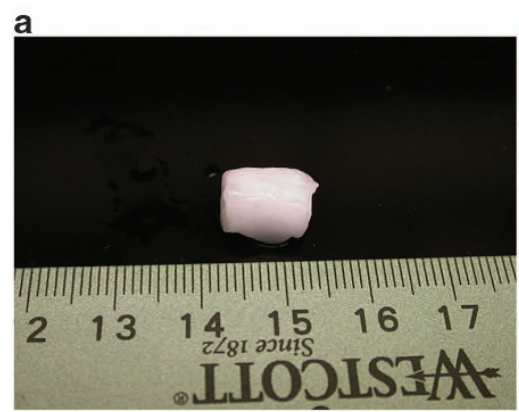

e

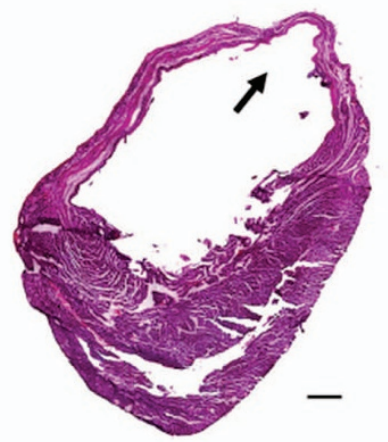

b

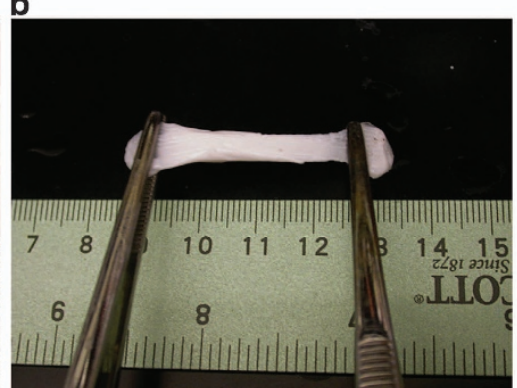

C

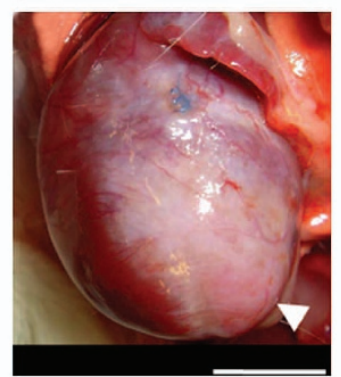

d

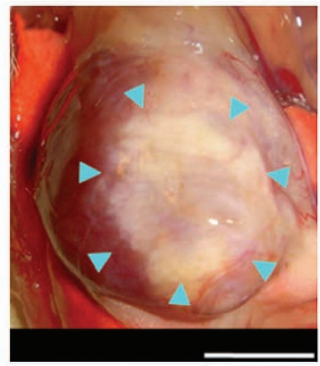

$f$

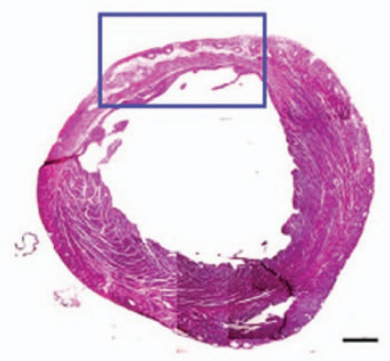

g

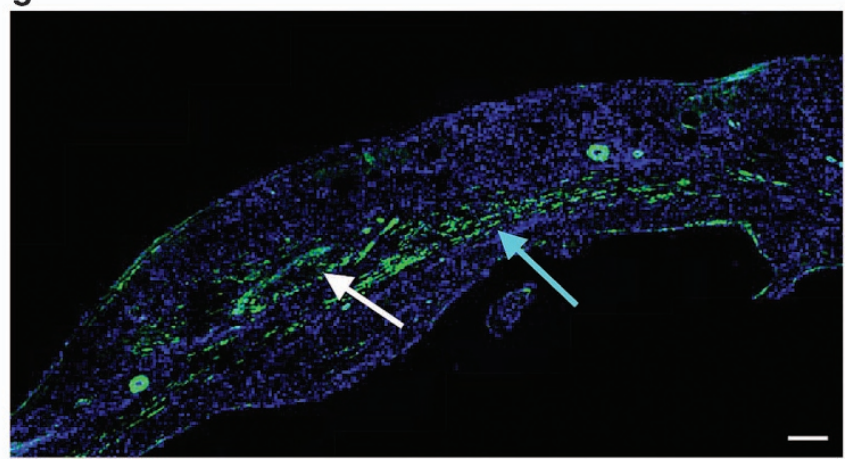

Figure 1 The gross morphology of a NIPAAm-Co-AAC-CO-HEMAPTMC hybrid hydrogel and experimental outcomes 8 weeks after implantation into rat myocardium following MI. (a) The composition of the thermosensitive hydrogel was (NIPAAm-co-AAc-co-HEMAPTMC) (86/4/10). (b) The therapeutic hydrogel was highly stretchable. (c) The control experiment with phosphate-buffered saline (PBS) injection. (d) Image of the rat heart following hybrid hydrogel injection. (e) Histology analysis by hematoxylin/eosin (H\&E) staining for PBS-injected heart. (f) Histology results by H\&E staining for hybrid hydrogel-injected heart. (g) Immunohistochemistry results for tissue ingrowth in the injected hydrogel. ${ }^{23}$ Copyright (2009) with permission from Elsevier.

In this section, we will discuss emerging hydrogels with elastomeric, conductive and oxygen-releasing features that can be used to promote the formation of functional cardiac tissues.

\section{Elastomeric hydrogels}

Cardiac tissue is particularly challenging to engineer owing to its continuous exposure to mechanical deformations. The ideal hydrogel for cardiac tissue engineering should tolerate cyclic loading forces for the resulting construct to function properly. However, the majority of existing hydrogels are not highly elastic. Because of the elastic nature of cardiac tissues, tough and stretchable hydrogels are promising materials for generation of biomimetic constructs that are similar to their native counterparts. Previously, principles of both covalent and ionic crosslinking were used to fabricate polyacrylamide-alginate hydrogel blends using different ratios of both components. ${ }^{42}$ The resulting hydrogels were tough and extremely stretchable. Such hydrogels have high potential to repair myocardium due to their biomimetic mechanical properties.

More recently, resilin-like polypeptide (RLP) hydrogels were reported for cardiac tissue engineering applications. ${ }^{43}$ Hybrid hydrogels from RLP and PEG were fabricated by a Michael-type addition reaction. Assessment of mechanical properties of the hybrid constructs revealed that the resulting gels were highly resilient and demonstrated reversible elastic properties. Moreover, the encapsulated cells spread following 7 days of culture. The RLP-PEG hybrid gels are especially useful for engineering tissues that are under continuous loading forces, such as the cardiac muscle. The resulting gel can be used as an injectable biomaterial to repair myocardial disfunction.

Similarly, in another study highly elastic methacrylated tropoelastin (MeTro) hydrogels were synthesized by using recombinant human tropoelastin for cardiac tissue engineering. ${ }^{44}$ Micropatterns were created to align neonatal cardiomyocytes on these elastic substrates. It was found that the micropatterned elastic hydrogels promoted alignment of primary cardiac cells (Figure 2). In addition, maturation of cardiomyocytes was significantly improved on patterned gels compared with the cells that were seeded on flat substrates. This platform can potentially be used for regeneration of the cardiac muscle. The improvements in elasticity and stretchability of hydrogels could address issues of mechanical stability with current tissue models and result in functional biomimetic constructs.

\section{Conductive hydrogels}

The spontaneous beating behavior of the heart is controlled by the electroconductive networks within the cardiac tissue. ${ }^{3}$ If cells are not connected properly, electrical signals do not propagate, resulting in a decrease in the performance of the heart. Therefore, it may be of benefit to use conductive hydrogels to improve the beating rates of cardiac cells. In one study, chitosan was modified by aniline oligomers to synthesize electrically conductive and degradable hydrogels. ${ }^{45}$ Similarly, a mechanically stable conductive hydrogel was generated by electrodepositing paratoluenesulfonate within the heparinpoly(vinyl alcohol) network. ${ }^{46}$ The hybrid conductive hydrogels promoted cell growth compared with the control samples, which did not include electrodepositing paratoluenesulfonate. Another conductive polymer, polypyrrole, was incorporated into oligo (polyethylene glycol) fumarate hydrogels. ${ }^{47}$ The resulting composite hydrogel was shown to be photolabile and biodegradable. Because of its conductivity, the engineered composite has great potential for improving the contractile activity of the cardiac cells. 

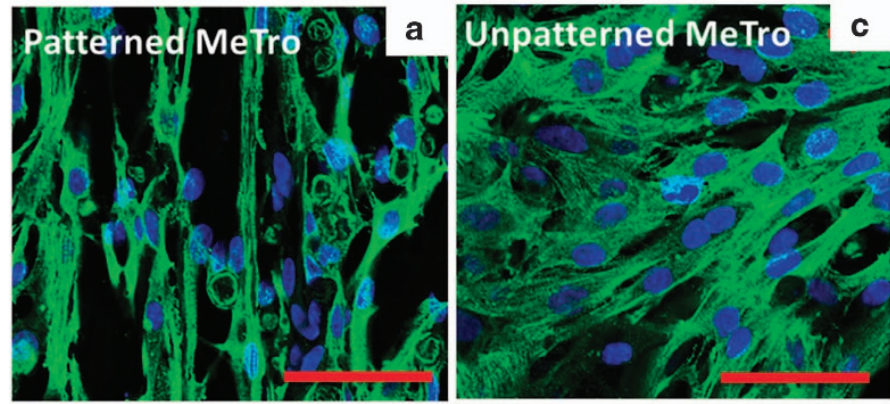

Troponin I/DAPI

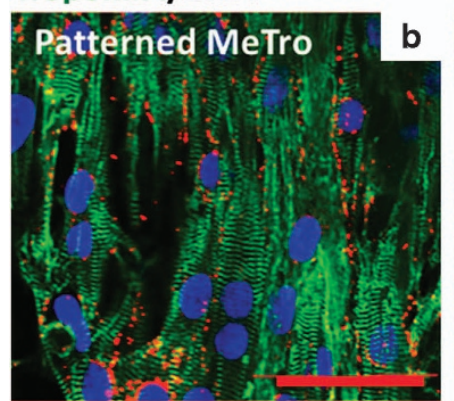

sarcomeric $\alpha$-actinin /connexin-43 /DAPI

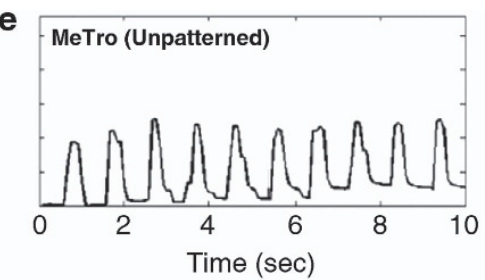

f
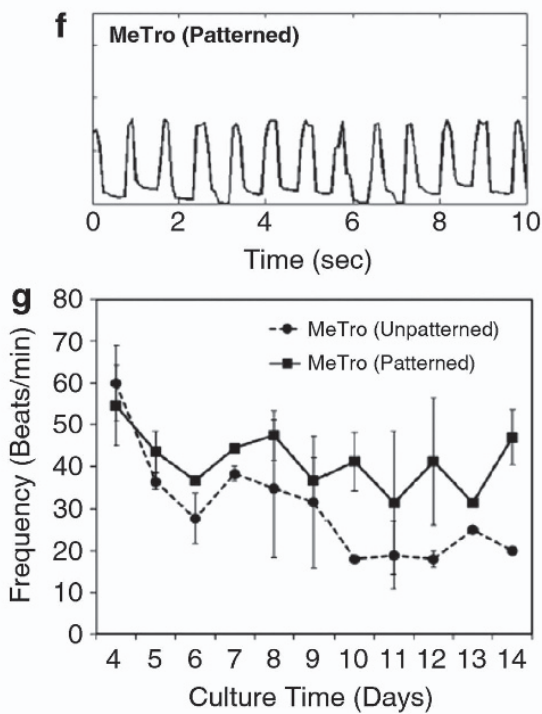

Figure 2 Expression of cardiac markers by primary rat cardiomyocytes on elastic hydrogels at day 8 and characterization of their beating. Immunostaining for (a) troponin I (green) and nuclei (blue) and (b) sarcomeric $\alpha$-actinin (green), connexin-43 (red) and nuclei (blue) revealed that the micropatterning process promoted alignment and maturation of cardiac cells. Immunostaining for (c) troponin I (green) and nuclei (blue) and (d) sarcomeric $\alpha$-actinin (green), connexin-43 (red) and nuclei (blue) for cardiac cells that were grown on unpatterned gels. (e) Beating behavior of cardiomyocytes on unpatterned elastic hydrogels. (f) Beating behavior of cardiomyocytes on patterned hydrogels. (g) Spontaneous beating rates of cardiomyoctes on both unpatterned and patterned hydrogels during two weeks of culture. ${ }^{44}$ Copyright (2013) with permission from John Wiley \& Sons, Inc.

In a more recent report, carbon nanotubes (CNTs) were embedded within gelatin-based hydrogels to yield hybrid biomaterials with improved mechanical properties and electrical conductivity. ${ }^{48}$ In this work, CNTs were incorporated in gelatin methacrylate (GelMA) hydrogels at different concentrations. The results demonstrated tunable mechanical properties for the hybrid hydrogels, which may greatly modulate the cell behavior in various tissue engineering applications, including cardiac regeneration. In a follow-up study, engineered cardiac patches were fabricated by seeding neonatal rat cardiomyoctes on CNT-reinforced GelMA hydrogel films. ${ }^{49}$ The highly porous electrically conductive hybrid constructs significantly improved cardiomyocyte adhesion, alignment, organization and maturation. Additionally, electrophysiological functions of the cardiomyocytes were improved. This system resulted in the formation of tubular and planar 3D free-standing actuators (Figure 3). Similarly, graphene oxide was incorporated into GelMA hydrogels to generate electrically conductive hydrogels. ${ }^{50}$ Development of such biocompatible conductive hydrogel systems is of vital importance for myocardial regeneration research.

Conductive nanowire reinforced patches were also developed for cardiac tissue engineering. ${ }^{34}$ Because of the poor conductive nature of currently available polymers, resulting cardiac patches do not function effectively. To tackle this hurdle, alginate hydrogels were loaded with conductive gold nanowires. Electrical communications between neighboring cardiomyocytes was significantly enhanced upon the addition of gold nanowires into alginate patches. Electrical stimulation improved the alignment of neonatal rat cardiomyocytes on the conductive material inducing synchronous contractions. The cardiac cells that were grown on the nanowired patches also demonstrated significantly higher expression of cardiac proteins. Such conductive biomaterials are anticipated to enhance the therapeutic efficiency of existing cardiac patches.

\section{Oxygen-releasing hydrogels}

Development of 3D thick tissues relies on the presence of a vascular supply. ${ }^{51}$ Cells do not receive sufficient oxygen and nutrients if they are located more than a few hundred micrometers away from blood vessels. $^{51-55}$ Oxygen-releasing biomaterials can be used as an alternative to provide adequate oxygen to cells. ${ }^{56,57}$ For example, fluorinated compounds ${ }^{58}$ or peroxides have been incorporated into scaffolds to enable the controlled release of oxygen. ${ }^{51,59}$ Such $3 \mathrm{D}$ biomimetic materials can be fabricated in the form of thin polymer films, ${ }^{60}$ electrospun fibers, ${ }^{61}$ porous scaffolds ${ }^{62}$ and hydrogels. ${ }^{63,64}$ The use of oxygen-releasing materials is particularly useful for providing sufficient amount of oxygen, especially during the early stages of in vitro cultures and in vivo implants. ${ }^{56,65}$ Thus, such systems may be beneficial for regeneration of damaged or diseased cardiac tissues. Despite their merits, however, these materials have a number of limitations. For example, the sustained release of oxygen over extended periods of time is a challenge and the byproducts of some of these systems may be toxic.

A common reagent for oxygen generation is hydrogen peroxide. ${ }^{66}$ However, this reagent induces rapid generation of oxygen, which is not desirable for cellular applications. Oxygen can also be 


\section{a Tightly rolled-up (50 $\mu \mathrm{m}$ thickness)}

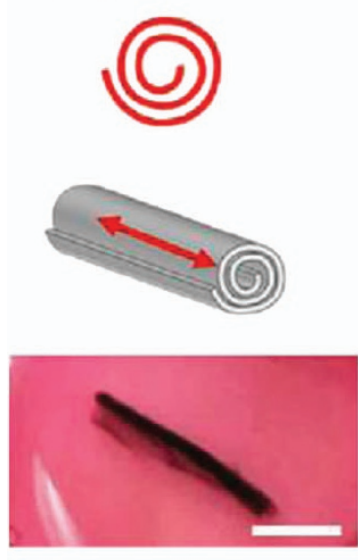

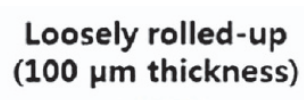
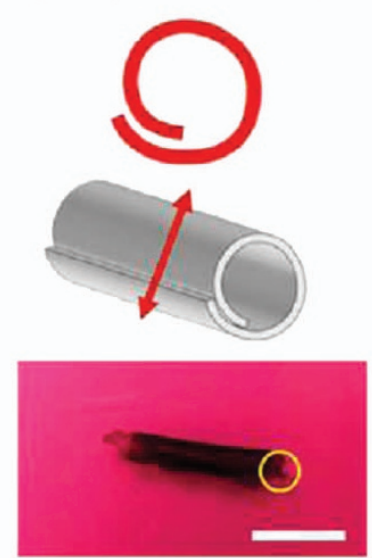

b

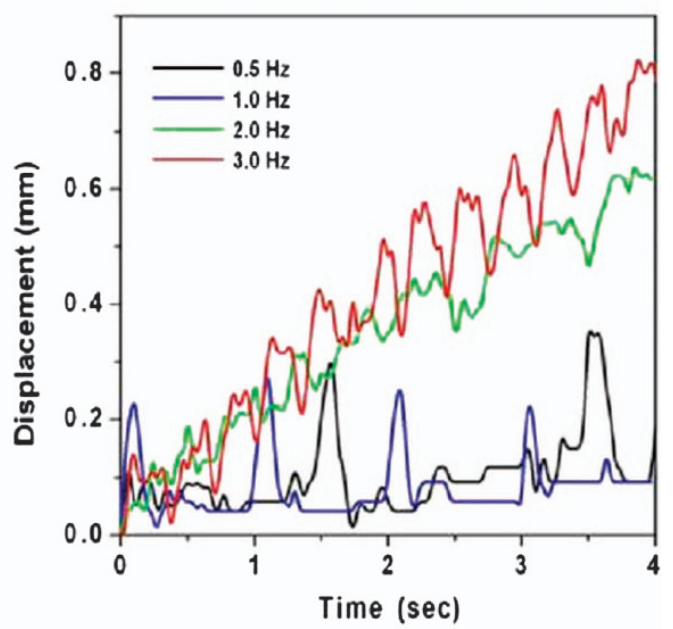

c
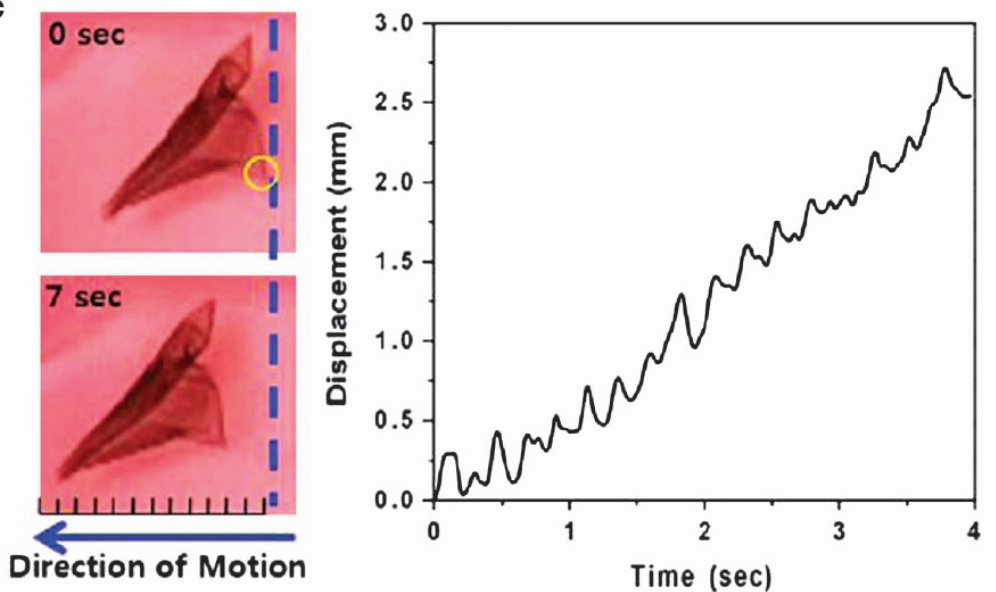

Figure 3 Free-standing hybrid actuators were fabricated by mixing CNTs and GelMA. (a) Beating directions of the actuators varied as a function of the thickness of the tubular constructs. (b) Displacement of the beating constructs was plotted against time upon electrical stimulation at different frequencies. (c) Spontaneous linear displacement of a triangular swimmer was plotted as a function of time. ${ }^{49}$ Copyright (2013) with permission from the American Chemical Society.

incorporated into biomaterials by means of solid peroxide compounds. ${ }^{56}$ For instance, solid reagents such as calcium peroxide, magnesium peroxide or sodium percarbonate can be incorporated into scaffolds to generate oxygen. When these solid compounds come into contact with water, they start producing oxygen. Because of the potential risks to induce cellular damage that may be caused by the generation of excess amount of free radicals, burst release of oxygen should be avoided. The oxygen release kinetics can be controlled by varying the degree of hydrophobicity of the material that is used to encapsulate solid peroxides, $\mathrm{pH}$, or temperature.

Oxygen-releasing hydrogels are a highly promising class of functional biomaterials for cardiac tissue engineering. ${ }^{56,57}$ To tackle diffusion limitations and form vascularized tissues, porous oxygenreleasing hydrogels can be used. For example, in a recent study the potential of an oxygen-generating thermoresponsive hydrogel to improve the viability and differentiation of cardiac stem cells towards regeneration of myocardial infarcted tissues was investigated. $^{64}$ In this work, hydrogen peroxide and poly(2vinlypyrridione) were encapsulated within poly(lactide-co-glycolide) microparticles. The oxygen-releasing microparticles were then incorporated into the thermoresponsive hydrogel precursor made of hydroxyethyl methacrylate-oligo(hydroxybutyrate), NIPAAm and AAc. The stiffness of the hydrogel was adjusted to be similar to that of the native heart muscle. Cardiosphere-derived cells (CDCs) were homogeneously encapsulated within the polymer precursor and cultured under hypoxic environment $\left(1 \% \mathrm{O}_{2}\right)$ for 14 days. The viability of CDCs was found to be significantly enhanced upon incorporation of oxygen-releasing microparticles. Furthermore, differentiation of the CDCs into cardiomyocytes was achieved within the oxygen-generating hydrogel under hypoxic conditions. This approach is expected to improve the generation of functional biomimetic constructs for repairing the ischemic cardiac tissue after MI and enhance the efficiency of existing cell delivery platforms.

\section{APPLICATIONS OF ENGINEERED HYDROGELS IN CARDIAC TISSUE ENGINEERING}

In the previous sections, we have discussed the major challenges associated with biomaterial properties in cardiac tissue engineering and the most plausible remedies to address these issues. Among the promising regenerative materials, hydrogels constitute a powerful class 
of substances for a broad range of biomedical applications, such as small molecule delivery, stem cell differentiation and tissue regeneration. The first step in obtaining biomimetic hydrogels is to synthesize and characterize the biomaterial that will be in contact with the cells by using material science manufacturing approaches. To achieve this aim, physical and chemical properties (for example, water content, swelling, conductivity, elasticity, toughness, protein adsorption) of the hydrogels are determined. Subsequently, biological properties are assessed by testing the cellular response upon incorporation of cells into the hydrogel by using tissue engineering approaches.

Cardiac tissue engineering aims to form constructs that can closely mimic the native heart muscle. Towards achieving this goal, it is crucial to utilize physiologically relevant material properties for proper cell function. Moreover, it is essential to use the most suitable cell source and supplementary biomolecules to obtain functional cardiac tissues. This has important implications in cardiac differentiation and vascularization processes. In this context, engineered hydrogels are emerging materials for directing stem cell differentiation and growth factor presentation to improve cell survival and vascularization processes. In the following section, we will summarize the use of hydrogels for generation of functional cardiac tissues.

\section{Directing stem cell differentiation into cardiac lineage}

Cells for cardiac tissue engineering should perform the appropriate function while not being rejected by the patient's immune system. So far, a wide range of different cell sources have been utilized in engineering cardiac tissues. ${ }^{6,9}$ For instance, primary cardiomyocytes, ${ }^{3,67}$ skeletal myoblasts, ${ }^{3,5,8,67,68}$ endothelial progenitor cells, ${ }^{8,67}$ amniotic fluid-derived stem cells, ${ }^{69}$ hematopoietic stem cells, ${ }^{5}$ embryonic stem cells (ESCs), ${ }^{3,5,8,9}$ adipose-derived stromal cells, ${ }^{9,67,70}$ induced pluripotent stem cells (iPSCs), ${ }^{3,5,8}$ cardiac progenitor cells (CPCs), ${ }^{2,5}$ adult cardiac stem cells, ${ }^{9,71}$ bone marrow cells, ${ }^{8,67}$ and mesenchymal stem cells (MSCs) ${ }^{3,8,9}$ have been used in efforts to regenerate the damaged myocardium. Because of the limited access to primary cardiomyocytes and their minimal capability for expansion in vitro, alternative cell sources were used as mentioned above. Among these cell types, stem cells have been shown to be greatly promising candidates for transplantation following $\mathrm{MI}$ to rebuild the damaged muscle and improve the function of the heart. In particular, MSCs, PSCs and CPCs have demonstrated high cardiac differentiation potential.

MSCs can differentiate into cardiomyocytes both in vitro and in vivo. In addition, MSCs have the ability to secrete growth factors, which can promote vascularization. ${ }^{72,73}$ Cardiac differentiation of MSCs was reported in vivo after implantation into the hearts of various animal models. ${ }^{72,73}$ However, only a limited population of MSCs are believed to differentiate into cardiomyocytes following transplantation. In vitro differentiation of MSCs into cardiac cells has been promoted by co-culturing them with cardiac cells ${ }^{74,75}$ or by using biochemicals such as 5-azacytidine. ${ }^{76,77}$ Additionally, more recently it was found that $3 \mathrm{D}$ cellular alignment could significantly promote differentiation of MSCs into cardiomyocytes without using chemical reagents or co-culturing with other cell types. ${ }^{78}$ In this work, MSCs were aligned within the 3D structure of elastic tissue constructs. The expression of cardiac markers was significantly promoted by the enhancement in alignment, demonstrating a potential for cardiac regeneration.

Similarly, PSCs, including ESCs and iPSCs, have been differentiated into cardiomyocytes. ${ }^{79-81}$ Recently, both $2 \mathrm{D}$ and $3 \mathrm{D}$ cardiac patches were fabricated by differentiating human ESCs into cardiomyocytes in fibrin-based matrices. ${ }^{79}$ After 2 weeks of culture, highly functionalized cardiac tissues were formed by the alignment of ESCs in microfabricated hydrogel matrices containing staggered elliptical pores (Figure 4). Immunostaining for cardiac markers exhibited expression of troponin T, sarcomeric $\alpha$-actinin, connexin-43 and myosin heavy chain in both $2 \mathrm{D}$ and $3 \mathrm{D}$ gels. However, longer sarcomeres were formed in 3D patches compared with their monolayer analogs. In addition, the expression of cardiac genes, responsible for contractile activity of cardiomyocytes, were significantly upregulated in $3 \mathrm{D}$ patches compared with $2 \mathrm{D}$, demonstrating the suitability of $3 \mathrm{D}$ environments for differentiation of ESCs into cardiomyogenic lineage.

Differentiation of PSCs into cardiac cells has been shown to be promoted by applying electrical or mechanical stimulation during in vitro culture. For example, it was found that cardiac differentiation of human ESCs were promoted by applying electrical stimulation using a bioreactor. ${ }^{82}$ In another study, it was demonstrated that uniaxial mechanical loading promoted the cardiomyocyte differentiation of human ESCs within 3D collagen hydrogels. ${ }^{83}$ It was found that the application of mechanical stimulation enhanced cardiomyocyte alignment, hypertrophy, proliferation as well as the formation of sarcomeric bands. To further improve the function of engineered cardiac tissue construct, ECs and stromal cells were co-cultured with ESC-derived cardiomyocytes to form a tissue construct containing highly vascularized networks. In addition, the use of co-cultures was shown to promote the proliferation of cardiomyocytes and facilitate the formation of vasculature in $3 \mathrm{D}$ constructs. The engineered cardiac tissues were also shown to integrate with the host myocardium after transplantation.

It has also been reported that native cardiac ECM can induce the differentiation of human ESC into cardiomyocytes without the use of exogenous growth factors. ${ }^{80}$ Human ESC-derived cardiomyocytes were encapsulated in hybrid hydrogels composed of decellularized cardiac ECM from porcine heart and collagen type I. It was found that the population of ESCs that express troponin T increased when a hydrogel with higher concentration of ECM was used. In addition, hydrogels with a high ECM content promoted the function and contractile activities of cardiac cells as evidenced by higher expression of troponin I and connexin-43 compared with low-concentration ECM gels or pure collagen gels. ${ }^{80}$ Similarly, functional human heart tissue was engineered by using human ESC-derived cardiomyocytes in a fibrin gel. ${ }^{84}$ Highly organized and oriented networks of sarcomeres were formed within the hydrogel matrix. In addition, the cells exhibited spontaneous contractions from 5 to 10 days after seeding up to 8 weeks of culture. ${ }^{84}$ In another study, photocrosslinkable PEGylated-fibrinogen was used to transplant human ESC-derived cardiomyocytes. ${ }^{81}$ Cell-loaded gels were delivered into the hearts of rats using a MI model. The post-MI ventricular performance significantly improved 30 days after delivery, demonstrating the capability of the hydrogel to act as a cardiomyocyte carrier without inducing unfavorable cardiac remodeling.

In addition to ESCs, recently iPSCs have been used as a promising cell source for in vitro cardiomyocyte differentiation studies. These cells were established by transduction of specific transcription factors (for example, Oct3/4, Lin28, Nanog, SOX2, Klf4, c-Myc) into mouse ${ }^{85}$ or human ${ }^{86,87}$ fibroblasts. In a recent study, artificial cardiac tissues were engineered by differentiating human ESCs and iPSCs into cardiomyocytes using collagen type I and Matrigel. ${ }^{88}$ It was shown that the function and contractile properties of engineered cardiac tissues could be significantly improved by the addition of ascorbic acid and application of cyclic stretching. Differentiation of cardiomyocytes from iPSCs can provide an autologous cell source 

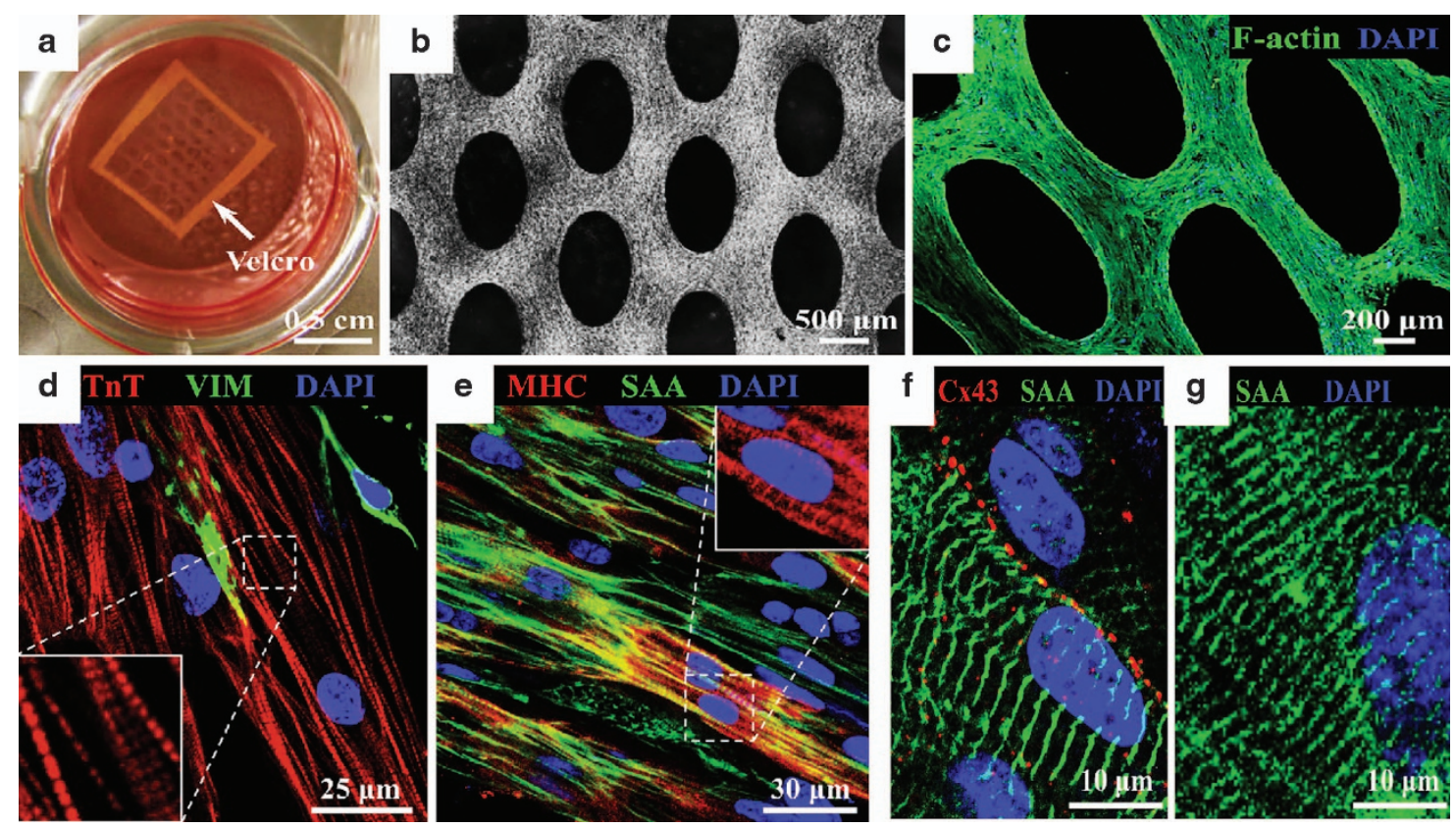

Figure 4 Functional cardiac patches were fabricated using human ESC-derived cardiomyocytes. (a) Representative image from a cardiac patch after 2 weeks of in vitro culture. (b) Microfabricated gels contained elliptical pores. (c) Aligned human ESCs within the hydrogels. Immunostaining of different cardiac markers, including (d) troponin T (red), (e) myosin heavy chain (red), (f) connexin-43 (red) and sarcomeric $\alpha$-actinin (green) by ESC-derived cardiomyocytes encapsulated within 3D gels after 2 weeks of in vitro culture. (g) Immunostaining for sarcomeric $\alpha$-actinin (green) on 2D gels, demonstrating decreased sarcomere length in 2D compared with 3D constructs. ${ }^{79}$ Copyright (2013) with permission from Elsevier.

for cardiac tissue engineering applications. In addition, iPSCs have shown great potential for investigating the mechanism of diseases and drug screening applications. However, some of the limitations associated with iPSC technology for clinical applications include possible formation of tumors in vivo and limited efficiency of their generation. ${ }^{89}$

CPCs that express stem cell factor protein receptor $(\mathrm{c}-\mathrm{Kit}+)$ and stem cell antigen 1 ( $\mathrm{Sca}-1$ ) possess the ability to differentiate into cardiomyocytes, smooth muscle cells and ECs. It has been shown that $\mathrm{c}-\mathrm{Kit}+\mathrm{CPCs}$ regulate cardiomyogenesis during in utero development ${ }^{90}$ and can differentiate into cardiomyocytes during cardiac hypertrophy. ${ }^{91} \mathrm{c}-\mathrm{Kit}+\mathrm{CPC}$ can be isolated from patients with various congenital heart defects, expanded in culture and differentiated towards the cardiomyogenic lineage. ${ }^{92}$ Recently, it was reported that $\mathrm{c}$-Kit + stem cells promoted the formation of myocardium containing a network of blood vessels 20 days after injection into the infarction site of adult rats. ${ }^{93}$ Similarly, intravascular delivery of c-Kit + stem cells through the coronary arteries of rats has been shown to promote myocardial regeneration and reduce infarct size in a less invasive manner compared with surgical procedures. ${ }^{94}$ Other studies have also shown in vivo differentiation of c-Kit + stem cells to smooth muscle cells and ECs was promoted by in vitro activation of cardiac cells with insulin-like growth factor (IGF) and hepatocyte growth factor. ${ }^{95}$ This resulted in the formation of capillaries, which were integrated with the host vasculature upon implantation. In addition, Sca-1 expressing stem cells isolated from the heart may have the capability to differentiate into cardiac cells after treatment with 5-azacytidine in vitro. However, their differentiation into cardiac cells occurred with fusion to host cells in some cases when they were intravenously delivered into an infarct site in myocardium. ${ }^{96}$ Despite significant success in using CPCs for cardiac tissue engineering, there are still challenges for clinical applications of CPC-derived cardiomyocytes, including their low differentiation efficiency and poor maturation behavior. As an alternative approach, combining CPCs with $2 \mathrm{D}$ and $3 \mathrm{D}$ hydrogel networks could improve their differentiation into cardiomyocytes. It is anticipated that the incorporation of $\mathrm{CPC}$ and $\mathrm{EC}$ co-cultures within hydrogel networks will potentially open a new avenue toward engineering $3 \mathrm{D}$ vascularized cardiac tissues.

Although stem cell therapies have enormous potential in regenerative medicine, there are still challenges associated with their use as a reliable cell source for cardiac tissue engineering applications. ${ }^{67}$ The ideal cell source for cardiac differentiation should be easily harvested, maintained in culture, proliferate, be compatible with the host immune system. It should also possess strong potential to differentiate into functional cardiomyocytes with proper function and contractile activity. The development of reliable and efficient methods of differentiation and maturation of patient-derived stem cells to cardiomyocytes, and their subsequent integration into hydrogel materials, can lead to significant progress in the development of stem-cell based therapies for the repair of myocardium.

\section{Growth factor delivery for cardiac tissue engineering}

To enhance the efficiency of current tissue engineering models, it may be of benefit to incorporate growth factors and small cytoprotective molecules into cell-laden hydrogels for cardiac regeneration. As tissue healing takes weeks to months, the ability to provide sustained and controlled delivery of small molecules is a crucial step forward for the development of clinically successful regenerative therapies.

Because of the very low survival and engraftment rates associated with cell delivery into the myocardium, small molecules have been used to enhance cellular viability and integration. ${ }^{9}$ Therapeutic potential of cells can be augmented by pre-treating them with growth 
a

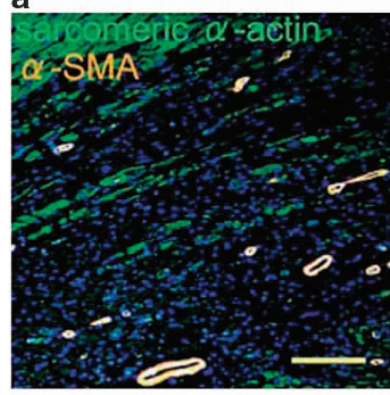

control

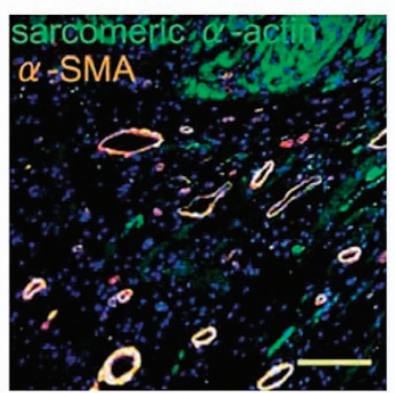

bFGF

c

$\star_{p}<0.005$
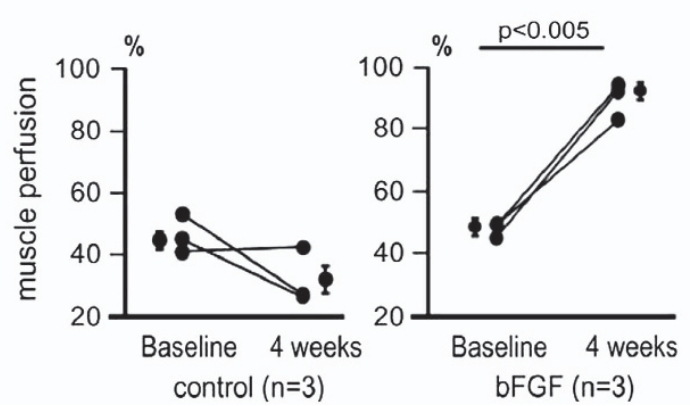

b
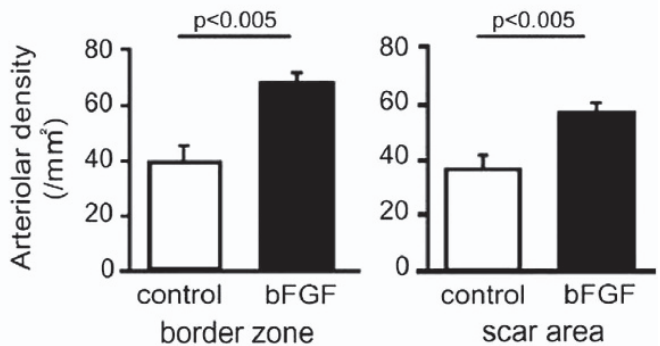

d

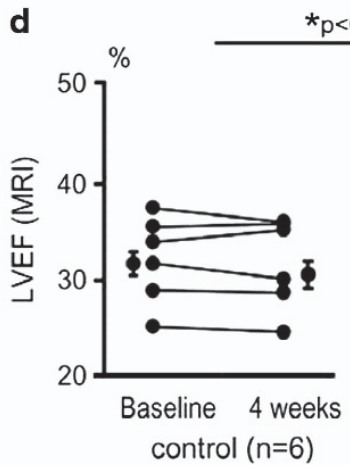

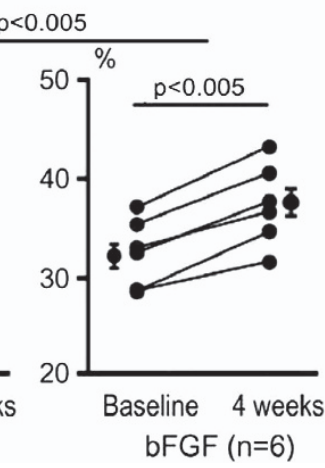

Figure 5 The influence of controlled release of bFGF from a gelatin-based hydrogel on restoring the cardiac function in a porcine model of myocardial infarction. (a) Immunostaining for alpha-SMA was used to compare the arterial density for control and bFGF included conditions. (b) bFGF that was delivered from a hydrogel gelatin patch enhanced the formation of arterial vessels. (c) Myocardial perfusion was significantly increased at 4 weeks when bFGF was used. (d) Left ventricular ejection fraction (LVEF) was significantly improved by bFGF at 4 weeks. ${ }^{104}$ Copyright (2008) with permission from the American College of Cardiology Foundation.

factors or cytokines to increase their attachment, survival, migration and differentiation capacity. ${ }^{9}$ For example, interleukin-8/Gro-a, stromal derived factor-1, vascular endothelial growth factor (VEGF), IGF-1, hepatocyte growth factor, fibroblast growth factor (FGF), integrin-linked kinase, Akt and glycogen synthase kinase have been extensively used to enhance viability and engraftment potential of delivered cells for cardiac therapy. ${ }^{9}$ The long-term goal is to differentiate the delivered stem cells into functional cardiomyocytes for regeneration of the damaged tissue. To enhance the differentiation of stem cells, cytokines and growth factors such as IGF-1, FGF, Wnt-5a, Wnt11, bone morphogenetic proteins 2 and 4, transforming growth factor-betal have previously been utilized. ${ }^{9}$

Hydrogels have been modified with small molecules for their sustained release over extended periods. ${ }^{97}$ Because of their delicate structures, protein-based materials may be challenging to chemically incorporate into hydrogels. In one study, cellulose polymers were covalently modified with a bioactive protein with a tunable rate of release. ${ }^{98}$ The therapeutic fusion protein SH3-rhFGF2 was produced in Escherichia coli and then attached to thiolated methyl cellulose via Michael-type addition reaction. The peptide-modified methyl cellulose was then mixed with hyaluronan to form hydrogels. The release of the fusion protein was characterized up to 10 days in vitro. This can be an attractive strategy in cardiac tissue engineering for localized delivery of cytoprotective growth factors. In other studies, IGF and VEGF delivery was shown to prevent cellular damage by apoptosis or necrosis. ${ }^{97,99}$

In addition to cell survival, small molecule/growth factor delivery can also be utilized to promote vascularization processes and improve functionality of tissue constructs. ${ }^{51,55,100,101}$ For example, in one study angiopoietin-1 and VEGF were incorporated into hyaluronan gels with and without heparin. ${ }^{102}$ The growth factors were retained within the gels due to their affinity to heparin. Formation of microvessels was found to be more pronounced in heparin-containing conditions in a mouse model. Similarly, sustained delivery of recombinant human VEGF was carried out within injectable alginate-based hydrogels. ${ }^{103} \mathrm{New}$ functional blood vessels were formed, and an improvement in the angiogenesis behavior was observed. This method is applicable for other growth factors and cell types and can be used for the generation of vascularized cardiac tissues in future.

Recently, basic FGF was incorporated in gelatin-based hydrogels and implanted in a pig model of chronic MI. ${ }^{104}$ Engraftment and differentiation of human CDCs in ischemic cardiac muscle were significantly improved by the controlled delivery of basic FGF from the hydrogel. Furthermore, perfusion and contractile properties of the pig myocardium were significantly enhanced due to the formation of microvascular networks (Figure 5). The results of this study are critical in the development of therapeutic approaches for human clinical trials to treat cardiac failure.

In addition to the release of a single growth factor over time, sequential delivery of growth factors is an alternative way to enhance myocardial repair. The feasibility of this approach was demonstrated through dual delivery of HGF and IGF-1 loaded in an injectable alginate gel in a rat model of acute MI. ${ }^{105}$ The scar fibrosis and infarct expansion were decreased, whereas formation of blood vessels and angiogenesis were increased in 4 weeks. As a result, restoration of myocardial tissue and cardiac function was promoted.

\section{CONCLUSIONS AND FUTURE OUTLOOK}

Cardiovascular disease is the leading cause of death globally. Because of the lack of organ donors, alternative approaches are essential for restoring the cardiac function after a heart attack. One strategy is to utilize tissue engineering platforms for generation of artificial 
constructs. The ability to fabricate properly functioning tissue replacement is dependent on the availability of biomimetic materials with highly tunable features.

Hydrogels are a potentially powerful class of biomaterials for cardiac tissue engineering. Hydrogel platforms have been widely utilized for controlling and directing cellular behavior. Functional hydrogels with responsive properties will be a key step toward engineering the heart and forming cardiac tissue substitutes in the future. For example, hydrogels that have the ability to mimic the mechanical properties of heart muscle may enable the generation of functional constructs for myocardial regeneration. The cardiac environment is highly dynamic, thus elastic materials are anticipated to better match the compliance of the tissue. In addition, elastomeric biomaterials can provide the flexibility and capacity for sustained cycles of expansion and contraction. Thus, tough and stretchable hydrogels may be beneficial for cardiac regeneration. Also, due to the electrophysiology of the native heart, conductive materials offer unique opportunities to enable the propagation of electrical signals during cardiac cell beating. Therefore, there is a growing demand for the synthesis of hydrogels that can enhance electrophysiological properties of cardiac cells within engineered constructs. To achieve this goal, hybrid hydrogels will be fabricated by incorporating conductive components into the scaffolds. In addition to elastomeric and conductive hydrogels, oxygen-releasing hydrogels are expected to make a significant impact toward the generation of biomimetic cardiac constructs. To form 3D tissues of clinically relevant sizes, it is essential to supply sufficient oxygen over an extended period of time in a sustained and controlled fashion. Consequently, porous oxygen-releasing hydrogels will help in tackling diffusion limitations and forming vascularized tissue mimetics.

In the future, it may be of great benefit to engineer biomaterials that have combined properties of elasticity and conductivity. For instance, conductive elastomers are highly promising next-generation materials for cardiac tissue engineering. Another direction for the future is merging microfabrication techniques with biomaterial design to engineer highly vascularized cardiac constructs with controlled architectures. The design of advanced bioreactors, which can be used to apply electrical and mechanical stimulation simultaneously on the engineered cardiac tissues, can be another useful research avenue. It is expected that functional hybrid hydrogels will enable us to mend the myocardium after injuries.

Other crucial elements to mimic the native cardiac tissue include incorporation of renewable cell sources and small biomolecules. In this context, it will be of great importance to utilize stem cells and growth factors in combination with micropatterning techniques to promote cardiogenic differentiation and vascularization events. We anticipate that pre-vascularized off-the-shelf cardiac tissues will meet the current needs of regenerative engineering and offer new opportunities for generation of novel tissue substitutes.

It is expected that hydrogel-based platforms with improved properties such as electrical conductivity, elasticity, vasculogenic potential, and oxygen supplementation will control and direct cellular behavior, resulting in the formation of functional cardiac tissues.

\section{ACKNOWLEDGEMENTS}

This paper was funded by the National Science Foundation CAREER Award (DMR 0847287), the Office of Naval Research Young National Investigator Award, the Presidential Early Career Award for Scientists and Engineers (PECASE) and the National Institutes of Health (EB012597, AR057837, DE021468, HL092836, DE019024, HL099073, EB008392).
1 Lloyd-Jones, D., Adams, R. J., Brown, T. M., Carnethon, M., Dai, S., De Simone, G., Ferguson, T. B., Ford, E., Furie, K., Gillespie, C., Go, A., Greenlund, K., Haase, N., Hailpern, S., Ho, P. M., Howard, V., Kissela, B., Kittner, S., Lackland, D., Lisabeth, L., Marelli, A., McDermott, M. M., Meigs, J., Mozaffarian, D., Mussolino, M., Nichol, G., Roger, V. L., Rosamond, W., Sacco, R., Sorlie, P., Stafford, R., Thom, T., Wasserthiel-Smoller, S., Wong, N. D. \& Wylie-Rosett, J. Heart disease and stroke statistics-2010 update: a report from the American Heart Association. Circulation 121, E46-E215 (2010).

2 Pedron, S., van Lierop, S., Horstman, P., Penterman, R., Broer, D. J. \& Peeters, E. Stimuli responsive delivery vehicles for cardiac microtissue transplantation. Adv. Funct. Mater. 21, 1624-1630 (2011).

3 Li, Z. Q. \& Guan, J. J. Hydrogels for cardiac tissue engineering. Polymers 3, 740-761 (2011).

4 Wang, F. \& Guan, J. J. Cellular cardiomyoplasty and cardiac tissue engineering for myocardial therapy. Adv. Drug Deliver. Rev. 62, 784-797 (2010).

5 Alcon, A., Bozkulak, E. C. \& Qyang, Y. B. Regenerating functional heart tissue for myocardial repair. Cell Mol. Life Sci. 69, 2635-2656 (2012).

6 Olson, J. L., Atala, A. \& Yoo, J. J. Tissue engineering: current strategies and future directions. Chonnam Med. J 47, 1-13 (2011).

7 Cezar, C. A., Mortisen, D. J. \& Ratner, B. D. Protein-immobilized poly(2-hydroxyethyl methacrylate-co-methacrylic acid) hydrogels for cardiac tissue engineering. J. Undergraduate Res. Bioeng. 7, 7-12 (2007).

8 Sui, R. Q., Liao, X. B., Zhou, X. M. \& Tan, Q. The current status of engineering myocardial tissue. Stem Cell Rev. Rep. 7, 172-180 (2011).

9 Chavakis, E., Koyanagi, M. \& Dimmeler, S. Enhancing the outcome of cell therapy for cardiac repair progress from bench to bedside and back. Circulation 121, 325-335 (2010).

10 Hofmann, M., Wollert, K. C., Meyer, G. P., Menke, A., Arseniev, L., Hertenstein, B. Ganser, A., Knapp, W. H. \& Drexler, H. Monitoring of bone marrow cell homing into the infarcted human myocardium. Circulation 111, 2198-2202 (2005).

11 Bartunek, J., Sherman, W., Vanderheyden, M., Fernandez-Aviles, F., Wijns, W. \& Terzic, A. Delivery of biologics in cardiovascular regenerative medicine. Clin. Pharmacol. Ther. 85, 548-552 (2009).

12 Liu, J. B., Hu, Q. S., Wang, Z. L., Xu, C. S., Wang, X. H., Gong, G. R., Mansoor, A., Lee, J., Hou, M. X., Zeng, L. P., Zhang, J. R., Jerosch-Herold, M., Guo, T., Bache, R. J. \& Zhang, J. Y. Autologous stem cell transplantation for myocardial repair. Am. J. Physiol. Heart Circ. Physiol. 287, H501-H511 (2004).

13 Prabhakaran, M. P., Venugopal, J., Kai, D. \& Ramakrishna, S. Biomimetic material strategies for cardiac tissue engineering. Mater. Sci. Eng. C Mater. Biol. Appl. 31, 503-513 (2011).

14 Jabbarzadeh, E., Blanchette, J., Shazly, T., Khademhosseini, A., Camci-Unal, G. \& Laurencin, C. T. Vascularization of biomaterials for bone tissue engineering: current approaches and major challenges. Curr. Angiogenesis 1, 180-191 (2012).

15 Camci-Unal, G., Cuttica, D., Annabi, N., Demarchi, D. \& Khademhosseini, A. Synthesis and characterization of hybrid hyaluronic acid-gelatin hydrogels. Biomacromolecules 14, 1085-1092 (2013).

16 Kaji, H., Camci-Unal, G., Langer, R. \& Khademhosseini, A. Engineering systems for the generation of patterned co-cultures for controlling cell-cell interactions. Biochim. Biophys. Acta 1810, 239-250 (2011).

17 DeForest, C. A. \& Anseth, K. S. Advances in bioactive hydrogels to probe and direct cell fate. Annu. Rev. Chem. Biomol. Eng. 3, 421-444 (2012).

18 Camci-Unal, G., Aubin, H., Ahari, A. F., Bae, H., Nichol, J. W. \& Khademhosseini, A. Surface-modified hyaluronic acid hydrogels to capture endothelial progenitor cells. Soft Matter 6, 5120-5126 (2010).

19 Camci-Unal, G., Nichol, J. W., Bae, H., Tekin, H., Bischoff, J. \& Khademhosseini, A Hydrogel surfaces to promote attachment and spreading of endothelial progenitor cells. J. Tissue Eng. Regen. Med. 7, 337-347 (2013).

20 Radisic, M., Park, H., Shing, H., Consi, T., Schoen, F. J., Langer, R., Freed, L. E. \& Vunjak-Novakovic, G. Functional assembly of engineered myocardium by electrical stimulation of cardiac myocytes cultured on scaffolds. Proc. Natl Acad. Sci. USA 101, 18129-18134 (2004).

21 Khalil, S. \& Sun, W. Bioprinting endothelial cells with alginate for 3D tissue constructs. J. Biomech. Eng. 131, 111002 (2009).

22 Walker, A. S., Blue, M. A., Brandon, T. A., Emmanual, J. \& Guilbeau, E. J. Performance of a hydrogel composite pericardial substitute after long-term implant studies. ASAIO J. 38, M550-M554 (1992).

23 Fujimoto, K. L., Ma, Z. W., Nelson, D. M., Hashizume, R., Guan, J. J., Tobita, K. \& Wagner, W. R. Synthesis, characterization and therapeutic efficacy of a biodegradable, thermoresponsive hydrogel designed for application in chronic infarcted myocardium. Biomaterials 30, 4357-4368 (2009).

24 Wang, H. B., Zhou, J., Liu, Z. Q. \& Wang, C. Y. Injectable cardiac tissue engineering for the treatment of myocardial infarction. J. Cell Mol. Med. 14, 1044-1055 (2010).

25 Davis, M. E., Hsieh, P. C. H., Takahashi, T., Song, Q., Zhang, S. G., Kamm, R. D., Grodzinsky, A. J., Anversa, P. \& Lee, R. T. Local myocardial insulin-like growth factor 1 (IGF-1) delivery with biotinylated peptide nanofibers improves cell therapy for myocardial infarction. Proc. Natl Acad. Sci. USA 103, 8155-8160 (2006).

26 Slaughter, B. V., Khurshid, S. S., Fisher, O. Z., Khademhosseini, A. \& Peppas, N. A. Hydrogels in regenerative medicine. Adv. Mater. 21, 3307-3329 (2009).

27 Peppas, N. A., Hilt, J. Z., Khademhosseini, A. \& Langer, R. Hydrogels in biology and medicine: from molecular principles to bionanotechnology. Adv. Mater. 18, 1345-1360 (2006) 
28 Piraino, F., Camci-Unal, G., Hancock, M. J., Rasponi, M. \& Khademhosseini, A Multi-gradient hydrogels produced layer by layer with capillary flow and crosslinking in open microchannels. Lab. Chip. 12, 659-661 (2012).

29 Hancock, M. J., Piraino, F., Camci-Unal, G., Rasponi, M. \& Khademhosseini, A. Anisotropic material synthesis by capillary flow in a fluid stripe. Biomaterials $\mathbf{3 2}$, 6493-6504 (2011).

30 Hosseini, V., Ahadian, S., Ostrovidov, S., Camci-Unal, G., Chen, S., Kaji, H., Ramalingam, M. \& Khademhosseini, A. Engineered contractile skeletal muscle tissue on a microgrooved methacrylated gelatin substrate. Tissue Eng. Part A 18, 2453-2465 (2012).

31 Ahadian, S., Ramon-Azcon, J., Ostrovidov, S., Camci-Unal, G., Hosseini, V., Kaji, H., Ino, K., Shiku, H., Khademhosseini, A. \& Matsue, T. Interdigitated array of P electrodes for electrical stimulation and engineering of aligned muscle tissue. Lab. Chip. 12, 3491-3503 (2012).

32 Birla, R. K., Borschel, G. H., Dennis, R. G. \& Brown, D. L. Myocardial engineering in vivo: formation and characterization of contractile, vascularized three-dimensional cardiac tissue. Tissue Eng. 11, 803-813 (2005)

33 Zustiak, S. P., Wei, Y. Q. \& Leach, J. B. Protein-hydrogel interactions in tissue engineering: mechanisms and applications. Tissue Eng. Part B 19, 160-171 (2013).

34 Dvir, T., Timko, B. P., Brigham, M. D., Naik, S. R., Karajanagi, S. S., Levy, O., Jin, H., Parker, K. K., Langer, R. \& Kohane, D. S. Nanowired three-dimensional cardiac patches. Nat. Nanotechnol. 6, 720-725 (2011).

35 Jongpaiboonkit, L., King, W. J., Lyons, G. E., Paguirigan, A. L., Warrick, J. W., Beebe, D. J. \& Murphy, W. L. An adaptable hydrogel array format for 3-dimensional cell culture and analysis. Biomaterials 29, 3346-3356 (2008).

36 Young, J. L. \& Engler, A. J. Hydrogels with time-dependent material properties enhance cardiomyocyte differentiation in vitro. Biomaterials 32, 1002-1009 (2011).

37 Copland, I. B., Jolicoeur, E. M., Gillis, M. A., Cuerquis, J., Eliopoulos, N., Annabi, B. Calderone, A., Tanguay, J. F., Ducharme, A. \& Galipeau, J. Coupling erythropoietin secretion to mesenchymal stromal cells enhances their regenerative properties. Cardiovasc. Res. 79, 405-415 (2008).

38 Giraud, M.-N., Ayuni, E., Cook, S., Siepe, M., Carrel, T. P. \& Tevaearai, H. T. Hydrogelbased engineered skeletal muscle grafts normalize heart function early after myocardial infarction. Artif. Organs 32, 692-700 (2008).

39 Black, L. D. III, Meyers, J. D., Weinbaum, J. S., Shvelidze, Y. A. \& Tranquillo, R. T. Cell-induced alignment augments twitch force in fibrin gel-based engineered myocardium via gap junction modification. Tissue Eng. Part A 15, 3099-3108 (2009).

40 Huang, Y. C., Khait, L. \& Birla, R. K. Contractile three-dimensional bioengineered heart muscle for myocardial regeneration. J. Biomed. Mater. Res. A 80A, 719-731 (2007).

41 Singelyn, J. M., DeQuach, J. A., Seif-Naraghi, S. B., Littlefield, R. B., Schup-Magoffin, P. J. \& Christman, K. L. Naturally derived myocardial matrix as an injectable scaffold for cardiac tissue engineering. Biomaterials 30, 5409-5416 (2009).

42 Sun, J.-Y., Zhao, X., Illeperuma, W. R. K., Chaudhuri, O., Oh, K. H., Mooney, D. J., Vlassak, J. J. \& Suo, Z. Highly stretchable and tough hydrogels. Nature 489 133-136 (2012).

43 McGann, C. L., Levenson, E. A. \& Kiick, K. L. Resilin-based hybrid hydrogels for cardiovascular tissue engineering. Macromol. Chem. Phys. 214, 203-213 (2013).

44 Annabi, N., Tsang, K., Mithieux, S. M., Nikkhah, M., Ameri, A., Khademhosseini, A. \& Weiss, A. S. Highly elastic micropatterned hydrogel for engineering functional cardiac tissue. Adv. Funct. Mater. 23, 4950-4959 (2013).

45 Guo, B., Finne-Wistrand, A. \& Albertsson, A.-C. Facile synthesis of degradable and electrically conductive polysaccharide hydrogels. Biomacromolecules 12, 2601-2609 (2011).

46 Green, R. A., Hassarati, R. T., Goding, J. A., Baek, S., Lovell, N. H., Martens, P. J. \& Poole-Warren, L. A. Conductive hydrogels: mechanically robust hybrids for use as biomaterials. Macromol. Biosci. 12, 494-501 (2012).

47 Runge, M. B., Dadsetan, M., Baltrusaitis, J., Ruesink, T., Lu, L., Windebank, A. J. \& Yaszemski, M. J. Development of electrically conductive oligo(polyethylene glycol) fumarate-polypyrrole hydrogels for nerve regeneration. Biomacromolecules 11, 2845-2853 (2010)

48 Shin, S. R., Bae, H., Cha, J. M., Mun, J. Y., Chen, Y. C., Tekin, H., Shin, H., Farshchi, S., Dokmeci, M. R., Tang, S. \& Khademhosseini, A. Carbon nanotube reinforced hybrid microgels as scaffold materials for cell encapsulation. ACS Nano 6, 362-372 (2012).

49 Shin, S. R., Jung, S. M., Zalabany, M., Kim, K., Zorlutuna, P., Kim, S. B., Nikkhah, M., Khabiry, M., Azize, M., Kong, J., Wan, K. T., Palacios, T., Dokmeci, M. R., Bae, H., Tang, X. S. \& Khademhosseini, A. Carbon nanotube-embedded hydrogel sheets for engineering cardiac constructs and bioactuators. ACS Nano 7, 2369-2380 (2013).

50 Shin, S. R., Aghaei-Ghareh-Bolagh, B., Dang, T. T., Topkaya, S. N., Gao, X., Yang, S. Y., Jung, S. M., Oh, J. H., Dokmeci, M. R., Tang, X. S. \& Khademhosseini, A Cell-laden microengineered and mechanically tunable hybrid hydrogels of gelatin and graphene oxide. Adv. Mater. 25, 6385-6391 (2013).

51 Ko, H. C. H., Milthorpe, B. K. \& McFarland, C. D. Engineering thick tissues-the vascularisation problem. Eur. Cells Mater. 14, 1-18 (2007)

52 Sheridan, M. H., Shea, L. D., Peters, M. C. \& Mooney, D. J. Bioadsorbable polymer scaffolds for tissue engineering capable of sustained growth factor delivery. J. Control. Release 64, 91-102 (2000).

53 Okano, T. \& Matsuda, T. Muscular tissue engineering: capillary-incorporated hybrid muscular tissues in vivo tissue culture. Cell. Transplant. 7, 435-442 (1998).

54 Frerich, B., Lindemann, N., Kurtz-Hoffmann, J. \& Oertel, K. In vitro model of a vascular stroma for the engineering of vascularized tissues. Int. J. Oral Maxillofac. Surg. 30, 414-420 (2001).
55 Lovett, M., Lee, K., Edwards, A. \& Kaplan, D. L. Vascularization strategies for tissue engineering. Tissue Eng. Part B 15, 353-370 (2009).

56 Camci-Unal, G., Alemdar, N., Annabi, N. \& Khademhosseini, A. Oxygen releasing biomaterials for tissue engineering. Polym. Int. 62, 843-848 (2013).

57 Camci-Unal, G. \& Khademhosseini, A. Biomaterials that breathe. Chem. Ind. 77, 28-30 (2013)

58 Seifu, D. G., Isimjan, T. T. \& Mequanint, K. Tissue engineering scaffolds containing embedded fluorinated-zeolite oxygen vectors. Acta Biomater. 7, 3670-3678 (2011).

59 Radisic, M., Park, H., Chen, F., Salazar-Lazzaro, E. J., Wang, Y., Dennis, R., Langer, R. Freed, L. \& Vunjak-Novakovic, G. Biomimetic approach to cardiac tissue engineering oxygen carriers and channeled scaffolds. Tissue Eng. 12, 2077-2091 (2006).

60 Harrison, B. S., Eberli, D., Lee, S. J., Atala, A. \& Yoo, J. J. Oxygen producing biomaterials for tissue regeneration. Biomaterials 28, 4628-4634 (2007).

61 Wang, J., Zhu, Y., Bawa, H. K., Ng, G., Wu, Y., Libera, M., van der Mei, H. C., Busscher, H. J. \& Yu, X. Oxygen-generating nanofiber cell scaffolds with antimicrobial properties. ACS Appl. Mater. Interfaces 3, 67-73 (2011).

62 Oh, S. H., Ward, C. L., Atala, A., Yoo, J. J. \& Harrison, B. S. Oxygen generating scaffolds for enhancing engineered tissue survival. Biomaterials 30, 757-762 (2009).

63 Pedraza, E., Coronel, M. M., Fraker, C. A., Ricordi, C. \& Stabler, C. L. Preventing hypoxia-induced cell death in beta cells and islets via hydrolytically activated, oxygengenerating biomaterials. Proc. Natl Acad. Sci. USA 109, 4245-4250 (2012).

$64 \mathrm{Li}, \mathrm{Z}$., Guo, X. \& Guan, J. An oxygen release system to augment cardiac progenitor cell survival and differentiation under hypoxic condition. Biomaterials 33, 5914-5923 (2012).

65 Lewis, M. C., MacArthur, B. D., Malda, J., Pettet, G. \& Please, C. P. Heterogeneous proliferation within engineered cartilaginous tissue: the role of oxygen tension. Biotechnol. Bioeng. 91, 607-615 (2005).

66 Bae, S. E., Son, J. S., Park, K. \& Han, D. K. Fabrication of covered porous PLGA microspheres using hydrogen peroxide for controlled drug delivery and regenerative medicine. J. Control. Release 133, 37-43 (2009).

67 Finosh, G. T. \& Jayabalan, M. Regenerative therapy and tissue engineering for the treatment of end-stage cardiac failure. Biomatter 2, 1-14 (2012).

68 Menasche, P., Hagege, A. A., Vilquin, J. T., Desnos, M., Abergel, E., Pouzet, B., Bel, A., Sarateanu, S., Scorsin, M., Schwartz, K., Bruneval, P., Benbunan, M., Marolleau, J. P. \& Duboc, D. Autologous skeletal myoblast transplantation for severe postinfarction left ventricular dysfunction. J. Am. Coll. Cardiol. 41, 1078-1083 (2003).

69 Connell, J. P., Camci-Unal, G., Khademhosseini, A. \& Jacot, J. G. Amniotic fluidderived stem cells for cardiovascular tissue engineering applications. Tissue Eng. Part B 19, 368-379 (2013).

70 Madonna, R., Geng, Y. J. \& De Caterina, R. Adipose tissue-derived stem cells characterization and potential for cardiovascular repair. Arterioscler. Thromb. Vasc. Biol. 29, 1723-1729 (2009).

71 Bauer, M., Kang, L. F., Qu, Y. L., Wu, J. H., Peng, M., Chen, H. H., Camci-Unal, G., Bayomy, A. F., Sosnovik, D. E., Khademhosseini, A. \& Liao, R. Adult cardiac progenitor cell aggregates exhibit survival benefit both in vitro and in vivo. PLOS One 7, e50491 (2012)

72 Quevedo, H. C., Hatzistergos, K. E., Oskouei, B. N., Feigenbaum, G. S., Rodriguez, J. E., Valdes, D., Pattany, P. M., Zambrano, J. P., Hu, Q., McNiece, I., Heldman, A. W. \& Hare, J. M. Allogeneic mesenchymal stem cells restore cardiac function in chronic ischemic cardiomyopathy via trilineage differentiating capacity. Proc. Natl Acad. Sci. USA 106, 14022-14027 (2009).

73 Cho, J., Zhai, P., Maejima, Y. \& Sadoshima, J. Myocardial injection with GSK-3betaoverexpressing bone marrow-derived mesenchymal stem cells attenuates cardiac dysfunction after myocardial infarction. Circ. Res. 108, 478-489 (2011).

74 Cho, J., Rameshwar, P. \& Sadoshima, J. Distinct roles of glycogen synthase kinase (GSK)-3alpha and GSK-3beta in mediating cardiomyocyte differentiation in murine bone marrow-derived mesenchymal stem cells. J. Biol. Chem. 284, 36647-36658 (2009).

75 Pijnappels, D. A., Schalij, M. J., Ramkisoensing, A. A., van Tuyn, J., de Vries, A. A., van der Laarse, A., Ypey, D. L. \& Atsma, D. E. Forced alignment of mesenchymal stem cells undergoing cardiomyogenic differentiation affects functional integration with cardiomyocyte cultures. Circ. Res. 103, 167-176 (2008).

76 Yang, M. C., Wang, S. S., Chou, N. K., Chi, N. H., Huang, Y. Y., Chang, Y. L., Shieh, M. J. \& Chung, T. W. The cardiomyogenic differentiation of rat mesenchymal stem cells on silk fibroin-polysaccharide cardiac patches in vitro. Biomaterials $\mathbf{3 0}$, 3757-3765 (2009).

77 Feng, C., Zhu, J., Zhao, L., Lu, T., Zhang, W., Liu, Z. \& Tian, J. Suberoylanilide hydroxamic acid promotes cardiomyocyte differentiation of rat mesenchymal stem cells. Exp. Cell Res. 315, 3044-3051 (2009).

78 Guan, J., Wang, F., Li, Z., Chen, J., Guo, X., Liao, J. \& Moldovan, N. I. The stimulation of the cardiac differentiation of mesenchymal stem cells in tissue constructs that mimic myocardium structure and biomechanics. Biomaterials 32, 5568-5580 (2011).

79 Zhang, D., Shadrin, I. Y., Lam, J., Xian, H.-Q., Snodgrass, H. R. \& Bursac, N Tissue-engineered cardiac patch for advanced functional maturation of human ESC-derived cardiomyocytes. Biomaterials 34, 5813-5820 (2013).

80 Duan, Y., Liu, Z., O'Neill, J., Wan, L. Q., Freytes, D. O. \& Vunjak-Novakovic, G. Hybrid gel composed of native heart matrix and collagen induces cardiac differentiation of human embryonic stem cells without supplemental growth factors. J. Cardiovasc. Transl. Res. 4, 605-615 (2011).

81 Habib, M., Shapira-Schweitzer, K., Caspi, O., Gepstein, A., Arbel, G., Aronson, D. Seliktar, D. \& Gepstein, L. A combined cell therapy and in-situ tissue-engineering approach for myocardial repair. Biomaterials 32, 7514-7523 (2011). 
82 Serena, E., Figallo, E., Tandon, N., Cannizzaro, C., Gerecht, S., Elvassore, N. \& Vunjak-Novakovic, G. Electrical stimulation of human embryonic stem cells: cardiac differentiation and the generation of reactive oxygen species. Exp. Cell Res. 315, 3611-3619 (2009)

83 Tulloch, N. L., Muskheli, V., Razumova, M. V., Korte, F. S., Regnier, M., Hauch, K. D., Pabon, L., Reinecke, H. \& Murry, C. E. Growth of engineered human myocardium with mechanical loading and vascular coculture. Circ. Res. 109, 47-59 (2011).

84 Schaaf, S., Shibamiya, A., Mewe, M., Eder, A., Stohr, A., Hirt, M. N., Rau, T., Zimmermann, W. H., Conradi, L., Eschenhagen, T. \& Hansen, A. Human engineered heart tissue as a versatile tool in basic research and preclinical toxicology. PLoS One 6, e26397 (2011)

85 Takahashi, K. \& Yamanaka, S. Induction of pluripotent stem cells from mouse embryonic and adult fibroblast cultures by defined factors. Cell 126, 663-676 (2006).

86 Takahashi, K., Tanabe, K., Ohnuki, M., Narita, M., Ichisaka, T., Tomoda, K. \& Yamanaka, S. Induction of pluripotent stem cells from adult human fibroblasts by defined factors. Cell 131, 861-872 (2007).

87 Yu, J., Vodyanik, M. A., Smuga-Otto, K., Antosiewicz-Bourget, J., Frane, J. L. Tian, S., Nie, J., Jonsdottir, G. A., Ruotti, V., Stewart, R., Slukvin, I. I. \& Thomson, J. A. Induced pluripotent stem cell lines derived from human somatic cells. Science 318, 1917-1920 (2007).

88 Kensah, G., Roa Lara, A., Dahlmann, J., Zweigerdt, R., Schwanke, K., Hegermann, J., Skvorc, D., Gawol, A., Azizian, A., Wagner, S., Maier, L. S., Krause, A., Drager, G., Ochs, M., Haverich, A., Gruh, I. \& Martin, U. Murine and human pluripotent stem cell-derived cardiac bodies form contractile myocardial tissue in vitro. Eur. Heart J. 34, 1134-1146 (2013)

89 Yoshida, Y. \& Yamanaka, S. Recent stem cell advances: induced pluripotent stem cells for disease modeling and stem cell-based regeneration. Circulation 122, 80-87 (2010).

90 Ferreira-Martins, J., Ogorek, B., Cappetta, D., Matsuda, A., Signore, S., D’Amario, D., Kostyla, J., Steadman, E., Ide-Iwata, N., Sanada, F., Iaffaldano, G., Ottolenghi, S., Hosoda, T., Leri, A., Kajstura, J., Anversa, P. \& Rota, M. Cardiomyogenesis in the developing heart is regulated by c-kit-positive cardiac stem cells. Circ. Res. 110, 701-715 (2012).

91 Urbanek, K., Quaini, F., Tasca, G., Torella, D., Castaldo, C., Nadal-Ginard, B., Leri, A. Kajstura, J., Quaini, E. \& Anversa, P. Intense myocyte formation from cardiac stem cells in human cardiac hypertrophy. Proc. Natl Acad. Sci. USA 100, 10440-10445 (2003).

92 Mishra, R., Vijayan, K., Colletti, E. J., Harrington, D. A., Matthiesen, T. S., Simpson, D., Goh, S. K., Walker, B. L., Almeida-Porada, G., Wang, D., Backer, C. L., Dudley, S. C. Jr, Wold, L. E. \& Kaushal, S. Characterization and functionality of cardiac progenitor cells in congenital heart patients. Circulation 123, 364-373 (2011).

93 Beltrami, A. P., Barlucchi, L., Torella, D., Baker, M., Limana, F., Chimenti, S., Kasahara, H., Rota, M., Musso, E., Urbanek, K., Leri, A., Kajstura, J. Nadal-Ginard, B. \& Anversa, P. Adult cardiac stem cells are multipotent and support myocardial regeneration. Cell 114, 763-776 (2003).

94 Dawn, B. Stein, A. B., Urbanek, K., Rota, M. Whang, B., Rastaldo, R., Torella, D., Tang, X. L., Rezazadeh, A., Kajstura, J., Leri, A., Hunt, G., Varma, J., Prabhu, S. D., Anversa, P. \& Bolli, R. Cardiac stem cells delivered intravascularly traverse the vessel barrier, regenerate infarcted myocardium, and improve cardiac function. Proc. Nat Acad. Sci. USA 102, 3766-3771 (2005).

95 Tillmanns, J., Rota, M., Hosoda, T., Misao, Y., Esposito, G., Gonzalez, A., Vitale, S., Parolin, C., Yasuzawa-Amano, S., Muraski, J., De Angelis, A., LeCapitaine, N.,
Siggins, R. W., Loredo, M., Bearzi, C., Bolli, R., Urbanek, K., Leri, A., Kajstura, J. \& Anversa, P. Formation of large coronary arteries by cardiac progenitor cells. Proc. Natl Acad. Sci. USA 105, 1668-1673 (2008).

96 Oh, H., Bradfute, S. B., Gallardo, T. D., Nakamura, T., Gaussin, V., Mishina, Y., Pocius, J., Michael, L. H., Behringer, R. R., Garry, D. J., Entman, M. L. \& Schneider, M. D. Cardiac progenitor cells from adult myocardium: homing, differentiation, and fusion after infarction. Proc. Natl Acad. Sci. USA 100, 12313-12318 (2003).

97 Chen, F. M., Zhang, M. \& Wu, Z. F. Toward delivery of multiple growth factors in tissue engineering. Biomaterials 31, 6279-6308 (2010).

98 Vulic, K. \& Shoichet, M. S. Tunable growth factor delivery from injectable hydrogels for tissue engineering. J. Am. Chem. Soc. 134, 882-885 (2012).

99 Borselli, C., Storrie, H., Benesch-Lee, F., Shvartsman, D., Cezar, C., Lichtman, J. W., Vandenburgh, H. H. \& Mooney, D. J. Functional muscle regeneration with combined delivery of angiogenesis and myogenesis factors. Proc. Natl Acad. Sci. USA 107, 3287-3292 (2010).

100 Tabata, Y., Miyao, M., Ozeki, M. \& Ikada, Y. Controlled release of vascular endothelial growth factor by use of collagen hydrogels. J. Biomat. Sci. Polym. Ed. 11, 915-930 (2000).

101 Pieper, J. S., Hafmans, T., van Wachem, P. B., van Luyn, M. J. A., Brouwer, L. A., Veerkamp, J. H. \& van Kuppevelt, T. H. Loading of collagen-heparan sulfate matrices with bFGF promotes angiogenesis and tissue generation in rats. J. Biomed. Mater. Res. 62, 185-194 (2002)

102 Riley, C. M., Fuegy, P. W., Firpo, M. A., Shu, X Z Prestwich, G. D. \& Peattie, R. A Stimulation of in vivo angiogenesis using dual growth factor-loaded crosslinked glycosaminoglycan hydrogels. Biomaterials 27, 5935-5943 (2006).

103 Silva, E. A. \& Mooney, D. J. Spatiotemporal control of vascular endothelial growth factor delivery from injectable hydrogels enhances angiogenesis. J. Thromb. Haemost. 5, 590-598 (2007).

104 Takehara, N., Tsutsumi, Y., Tateishi, K., Ogata, T., Tanaka, H., Ueyama, T., Takahashi, T., Takamatsu, T., Fukushima, M., Komeda, M., Yamagishi, M., Yaku, H., Tabata, Y., Matsubara, H. \& Oh, H. Controlled delivery of basic fibroblast growth factor promotes human cardiosphere-derived cell engraftment to enhance cardiac repair for chronic myocardial infarction. J. Am. Coll. Cardiol. 52, 1858-1865 (2008).

105 Ruvinov, E., Leor, J. \& Cohen, S. The promotion of myocardial repair by the sequential delivery of IGF-1 and HGF from an injectable alginate biomaterial in a model of acute myocardial infarction. Biomaterials 32, 565-578 (2011).

(c) (i) $(9)$ This work is licensed under a Creative Commons Attribution-NonCommercial-NoDerivs 3.0 Unported License. The images or other third party material in this article are included in the article's Creative Commons license, unless indicated otherwise in the credit line; if the material is not included under the Creative Commons license, users will need to obtain permission from the license holder to reproduce the material. To view a copy of this license, visit http://creativecommons.org/licenses/by-nc-nd/3.0/ 


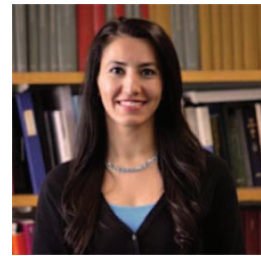

Gulden Camci-Unal received her PhD in Chemistry at Iowa State University (USA) and her MSc and BSc degrees both in Chemical Engineering at the Middle East Technical University (Turkey). Her research at the interface of biomaterials and bioengineering has made important contributions in generation of microengineered hydrogels for cardiovascular tissue engineering applications. Her work has been published in various high impact journals such as, Advanced Materials, JACS, Biomaterials, Lab on a Chip, Soft Matter, Tissue Engineering, Biomacromolecules, Journal of Tissue Engineering and Regenerative Medicine, PLOS One and Biochimica et Biophysica Acta. She is an editorial board member of Scientific Reports (Nature Publishing Group), Journal of Biomaterials and Tissue Engineering, and Regenerative Medicine Research. Gulden Camci-Unal is currently a post-doctoral fellow at Harvard University (USA).
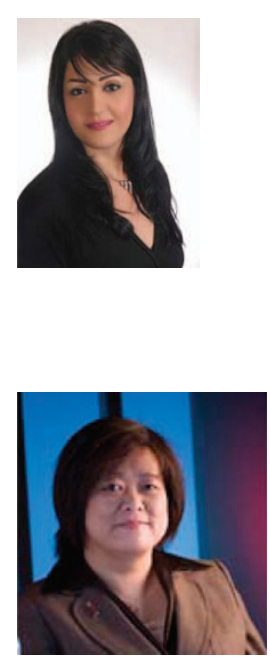

Nasim Annabi is a postdoctoral fellow at the Harvard-MIT Division of Health Sciences Technology, Brigham and Women's Hospital, and the Wyss Institute for Biologically Inspired Engineering at Harvard University. Her research is based on developing advanced biomaterials and combining them with microscale and nanoscale technologies to control cellular microenvironment and engineer complex 3D tissue constructs. She is an author of $>30$ articles in peer-reviewed journals, 7 book chapters/editorials, $>30$ abstracts and has 2 patents on the synthesis and use of innovative biomaterials and microscale technologies for biomedical applications.
Ronglih Liao is an associate professor at the Harvard Medical School and the Divisions of Cardiovascular Medicine and Genetics at Brigham and Women's Hospital. Dr Liao also serves as a principle faculty in the Harvard Stem Cell Institute. She received her PhD in Biophysics from the University of Alabama at Birmingham. Her laboratory has worked to understand the molecule mechanisms driving the pathogenesis of heart failure and to reverse these processes through cellular and molecular means. She has recognized expertise in the interrogation of cardiovascular physiology in whole animals, isolated hearts and cardiomyocytes and in the study of adult tissue-derived stem/progenitor cells.
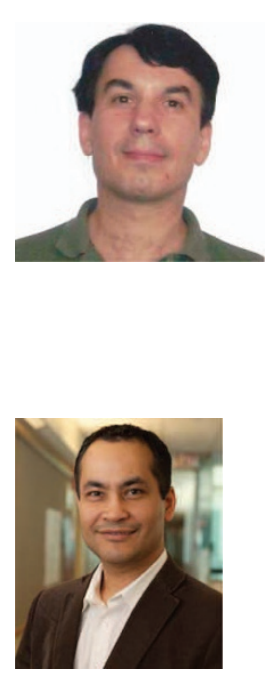

Mehmet R Dokmeci received BS (with distinction) and MS degrees from the University of Minnesota, Minneapolis and the PhD degree from the University of Michigan, Ann Arbor, MI, USA, all in electrical engineering. He is currently an Instructor at the Brigham and Women's Hospital, Harvard Medical School. His research is concentrated in all areas of microtechnologies and nanotechnologies and their applications to biomedical and optical devices, nanoscale integration, flexible electronics and implantable biosensors. He is the author of 56 technical journal articles and 98 conference publications, has one edited book, four invited book chapters and four patents.
Ali Khademhosseini is an Associate Professor at the Harvard-MIT Division of Health Sciences and Technology, Brigham and Women's Hospital and Harvard Medical School as well as an Associate Faculty at the Wyss Institute for Biologically Inspired Engineering and a Junior PI at the Japan's World Premier International-Advanced Institute for Materials Research at the Tohoku University where he directs a satellite laboratory. As of November 2013, he has authored $250+$ peer-reviewed journal papers ( $\mathrm{H}$-index $=54,>11500$ citations) and 90 book chapters/editorials. In addition, he has been invited to $200+$ invited/keynote lectures. Dr Khademhosseini's interdisciplinary research has been recognized by over 30 major national and international awards. He has received early career awards from three major engineering discipline societies: electrical (IEEE Engineering in Medicine and Biology Society award and IEEE Nanotechnology award), chemical (Colburn award from the AIChE), and mechanical engineering (Y.C. Fung award from the ASME). He is also a recipient of the Presidential Early Career Award for Scientists and Engineers, the highest honor given by the US government for early career investigators. He is a fellow of the American Institute of Medical and Biological Engineering (AIMBE) and the American Association for the Advancement of Science (AAAS). He is an Associate Editor for ACS Nano (IF: 12) and a standing member of NIH BTSS study section. He received his PhD in bioengineering from MIT (2005) and MASc (2001) and BASc (1999) degrees from the University of Toronto both in chemical engineering. Read more at: http://www.tissueeng.net/ 